\title{
Da Psicologia Social à Psicologia Societal ${ }^{1}$
}

\author{
Willem Doise ${ }^{2}$ \\ Universidade de Genebra
}

\begin{abstract}
RESUMO - O principal fator que diferencia os psicólogos sociais, para além dos diferentes paradigmas científicos, é sua posição em relação à legitimidade e à necessidade de uma psicologia societal. O objetivo desta psicologia sempre foi o de articular explicações no nível do indivíduo e explicações de ordem social, mostrando como o indivíduo dispõe de processos que lhe permitem funcionar em sociedade e, de uma maneira complementar, como as dinâmicas sociais, particularmente interacionistas, posicionais ou de valores e de crenças gerais, orientam o funcionamento desses processos.
\end{abstract}

Palavras-chave: psicologia societal; representações sociais; neveis de análise; direitos humanos.

\section{From Social Psychology to Societal Psychology}

\begin{abstract}
The main factor that diferenciates social psychologists beyond the different scientific paradigms is their position in relation to the legitimacy and the necessity of a societal psychology. Its objective was and continuess to be articulate explanationss at the individual level and explanationss of social order, showing howw individuals dispose process that allow them to function in society, and complementarily how social dinamics, particularly interacionists, positionaals or of values general belief systems, guide the working of these processes.
\end{abstract}

Key words: societal psychology; social representations; level of analyses; human rights

Há vários anos, os debates que ocorrem nos congressos internacionais de Psicologia Social se limitam, freqüentemente, a solicitações de esclarecimentos, a sugestões polidas de interpretações alternativas, a observações quanto às populações estudadas. Tudo se passa como se trabalhássemos no âmbito de uma ciência normatizada, uma ciência na qual os pesquisadores aderem aos mesmos postulados de base e na qual as possíveis divergências fossem apenas uma questão de detalhes.

Divergências fundamentais, no entanto, existem entre os pesquisadores, sendo que alguns aderem a um construcionismo radical, outros a uma prática da análise de discurso, rejeitando a idéia de quantificação ou variáveis experimentais e, outros ainda, aderem a uma corrente da cognição social que, ao contrário, privilegia a abordagem experimental. Mesmo quando, em uma mesma reunião, essas diferentes correntes são representadas, a prática habitual de simpósios e workshops acontecendo em paralelo, permite aos representantes das diferentes orientações não se encontrarem, permanecendo entre seus correligionários, e se me permitem dizer, evitando assim as guerras de religiões. Tais situações permitem o ataque à posições divergentes, sem que se estabeleça o contraditório.

Chega-se, assim, a situações que são pelo menos estranhas, como no caso de dois profundos conhecedores da produção contemporânea em psicologia social, Higgins e Kruglanski (1996), que editaram um volumoso Manual de Psicologia Social, sem que nele constasse a teoria das repre-

1 Tradução por Angela Maria de Oliveira Almeida.

2 Endereço: Université de Genève, FPSSE. 40, Bd du Pont d“Arve. CH1205. Genève, Suisse. E-mail: willem.doise@pse.unige.ch sentações sociais, mesmo que fosse em um único parágrafo. Salvo equívoco, o termo figura apenas duas vezes (na página 789), quando se questiona os diferentes significados que uma categorização pode assumir para o Eu e para o Outro. No índice remissivo o termo está ausente. Em um outro extremo, pode-se citar a abundante produção em psicologia social nos países da América Latina, a qual, a partir de observações pessoais e de uma análise mais sistemática realizada por Rateau e Rouquette (1998), sobre mais de 100 comunicações em psicologia social apresentadas no XXVI Congresso Interamericano de Psicologia, caracteriza-se por um tipo de recusa sistemática do método experimental, tão valorizado na América do Norte. Para citar Rateau e Rouquette sobre as comunicações na América Latina “...os problemas da sociedade são abundantemente representados, e estudados, na maioria das vezes, de maneira quase etnográfica em relação a um grupo particular..." (p. 175).

Deve-se, então, concluir que vivemos em mundos diferentes? A questão adquire sentido, e minha opinião é que o principal fator que diferencia os psicólogos sociais, para além dos diferentes paradigmas científicos, é sua posição em relação à possibilidade, ou mesmo à legitimidade e necessidade, de uma psicologia societal. São estes marcos que me levaram pessoalmente a praticar uma tal psicologia societal, que explanarei brevemente aqui, sem entretanto, preocuparme em colocá-los em uma ordem cronológica.

\section{Os níveis de análise e suas articulações}

Um dos objetivos dos trabalhos realizados em Genebra sobre influência social (cf. Mugny \& Doise, 1979), intergrupo e desenvolvimento social da inteligência (cf. Doise, 1982) 
foi sempre o de articular explicações de ordem individual com explicações de ordem societal; de mostrar como o indivíduo dispõe de processos que lhe permitem funcionar em sociedade e, de maneira complementar, como dinâmicas sociais, particularmente interacionais, posicionais ou de valores e de crenças gerais, orientam o funcionamento desses processos.

Uma perspectiva geral como essa necessita recorrer a quatro níveis de análise, que são, de fato, freqüentemente praticadas pelos psicólogos sociais, como mostra uma análise dos 7 primeiros volumes do European Journal of Social Psychology (Doise, 1980).

Um primeiro nível de análise focaliza o estudo dos processos intra-individuais. Os modelos utilizados tratam da maneira pela qual os indivíduos organizam suas experiências com o meio ambiente. Esse primeiro nível agrupa $46 \%$ das explicações presentes nos primeiros volumes do European Journal. Típico deste nível são as pesquisas sobre o equilíbrio cognitivo.

Um segundo nível descreve os processos inter-individuais e situacionais (27\% das explicações no corpus estudado). Os indivíduos são aqui considerados como intercambiáveis e são seus sistemas de interação que fornecem os princípios explicativos típicos das dinâmicas desse nível. As pesquisas sobre as redes de comunicação ilustram bem este nível, bem como as experiências com jogos de motivações mistas.

Um terceiro nível leva em conta as diferentes posições que os atores sociais ocupam no tecido das relações sociais, características de uma sociedade e analisa como suas posições modulam os processos do primeiro e segundo níveis (16\% das explicações). São, sobretudo, as pesquisas com grupos de status diferentes, dominantes e dominados, majoritários e minoritários, que se situam neste nível.

Um quarto nível remete-nos aos sistemas de crenças, representações, avaliações e normas sociais (aproximadamente uma explicação sobre dez). As produções culturais e ideológicas, características de uma sociedade ou de certos grupos, não somente dão significação aos comportamentos dos indivíduos, como também criam ou dão suporte às diferenciações sociais em nome de princípios gerais. Por exemplo, em nome de uma idéia ingênua de justiça, consideramos que as pessoas têm o destino que merecem.

Essa distinção em 4 níveis de análise não deve servir apenas a objetivos classificatórios. Ela deve, sobretudo, facilitar a realização de articulações de análises. Análises articulando vários níveis teóricos são mais completas; elas conduzem a uma melhor descrição de um processo conceitualizado em um dos níveis, precisando, prioritariamente, as condições de sua atualização, a partir dos outros níveis de análise. Em aproximadamente 40 artigos, dos 141 estudados, observase essas articulações de análises. Mas é verdade que as análises que recorriam às explicações do tipo societal (i. é. posicional e ideológica) eram minoritárias em psicologia social.

Uma confirmação de que o princípio geral das análises em níveis têm uma base sólida, foi-me dada pela sociologia. As teorias sociológicas não funcionariam sem recorrer, de uma maneira mais ou menos explícita, às conjecturas sobre o funcionamento individual ou inter-individual. Moscovici (1988) já demostrou isso nos sociólogos clássicos como Durkheim, Mauss, Weber e Simmel, e eu o demonstrei nos contemporâneos: Boudon, Crozier, Bourdieu e Touraine (Doise \& Lorenzi-Cioldi, 1989). Mas, se é verdade que as análises oriundas da psicologia ou da psicologia social completam, necessariamente, análises sociológicas, o inverso também é verdadeiro: explicações da psicologia social devem, necessariamente, ser completadas por explicações sociológicas, contribuindo, assim, para uma melhor compreensão dos jogos societais.

Esta foi uma lição que me ensinaram Serge Moscovici e Henri Tajfel, meus principais mestres em psicologia social e Jean Piaget, que também considero como um dos meus mestres nesta disciplina.

\section{O julgamento moral ou a psicologia societal de Piaget}

Ao reler O julgamento moral de Piaget (1932) não se pode deixar de ficar impressionado com a importância que ele atribui às análises do tipo societal para dar conta deste desenvolvimento. Não retomarei aqui, em detalhes, a análise desse trabalho e de outros escritos de Piaget dos anos 30, que desenvolvi para o livro editado por Garnier e Rouquette (2000).

O livro de Piaget sobre o julgamento moral é um verdadeiro livro de psicologia política, na medida em que ele esboça uma teoria que faz da interação democrática, da interação entre iguais, sem os entraves colocados pela autoridade, o principal motor do desenvolvimento moral. As condições em que se desenvolveu sua carreira o levaram, enquanto Diretor do Bureau International de l'Éducation(BIE), a interessar-se pelas relações internacionais, em um período dramático. No momento em que Hitler assume o poder, ele estende sua concepção da livre confrontação a um nível internacional, advogando por uma educação pela paz, nos seguintes termos:

... compreender pontos de vista diferentes dos seus, penetrar
na psicologia de outros povos, enfim, prever e explicar o que
mobiliza outros povos, é atualmente uma obrigação, mesmo
para o mais autêntico nacionalismo: sem essa adaptação, o
isolamento é fatal e sabemos a que conduz o isolamento em
um mundo onde tudo se relaciona no nivel econômico, politico
e das idéias. Ai está, portanto, o ponto de partida: o conheci-
mento dos outros como condição de sobrevivência e seguran-
ça nacionais e como meio de expansão da ideologia na qual se
acredita (Piaget, 1997, pp. 125-126).

As condições políticas, para uma verificação das teses de Piaget, não estavam postas. Seria no seio da Sociedade das Nações que o debate preconizado por Piaget deveria ser desencadeado, mas é pouco dizer que ele não pode acontecer. Quando Piaget dirigia esta mensagem ao Bureau International de l'Éducation, precursor da UNESCO, a Alemanha acabava de abandonar a Sociedade das Nações e a Itália não tardaria a fazer o mesmo. 
Pode-se perguntar se é por acaso que desde então o Psicólogo de Genebra interessou-se, sobretudo, pela descrição lógico-matemática de um pensamento socialmente descontextualizado? Quando ele aborda ainda problemas de ordem societal é para explicá-los a partir de uma nova forma de centração: o sociocentrismo. Ele o evoca para explicar o nacionalismo (Piaget \& Weil, 1951) ou a ideologia em geral (Piaget, 1965). Dito de outra forma, a intervenção do social é estudada como uma forma de viés, para retomar uma terminologia sociocognitivista.

\section{A teoria da identidade social}

Estranha história aquela da teoria da identidade social. Suas origens podem ser buscada em uma concepção "gestaltista" da percepção que, inicialmente, permitiu a Tajfel (1959) propor um modelo de acentuação relativa dos contrastes. Ele dava conta, assim, de um conjunto importante de resultados no âmbito dos julgamentos quantitativos. Em seguida, ele estende seu modelo, abordando o efeito da categorização na percepção (Tajfel \& Wilkes, 1963) e ao estudo dos estereótipos sociais (Tajfel, Skeikh \& Gardner, 1964).

Quando se debruça, em seguida, sobre o estudo das condições mínimas de aparição dos comportamentos discriminatórios (Tajfel, Billig, Bundy \& Flament, 1971), Tajfel marcará definitivamente o campo de estudo das relações intergrupos. Peço permissão para não descrever, novamente, um conjunto de pesquisas que já comentei abundantemente em várias oportunidades. Interessa-nos aqui a perspectiva societal que Tajfel introduzirá em suas explicações.

Quando apresentou pela primeira vez sua pesquisa, uma tal perspectiva é ainda mínima. Os resultados são explicados evocando a importância de uma norma genérica:

... é claro que interpretamos nossos resultados em função de uma norma social genérica de comportamento dentro e fora do grupo que orientou a escolha dos sujeitos. Isto aconteceu desta forma porque os sujeitos classificaram a situação social na qual eles se encontravam como uma situação onde essa norma era pertinente e onde a categorização social deveria conduzir a um comportamento intergrupo discriminatório muito mais do que a outras escolhas que lhe eram oferecidas (Tajfel, Billig, Bundy \& Flament, 1971, p.174).

De uma certa forma, a norma social toma aqui o status de uma boa forma "gestáltica", que seria ativada quando os grupos estão diante dela. Entretanto, Tajfel (1972) não demorou em desenvolver uma teoria mais complexa, fazendo intervir a comparação intergrupo como o motor da construção de uma identidade social positiva. Em artigos mais teóricos (Tajfel, 1974, 1975) ele estabelece uma relação entre esses resultados e uma ideologia de mudança social à qual certos grupos adotariam quando a única via possível para melhorar de vida é através de uma ação coletiva, visando mudar as relações entre grupos. De uma certa forma, os participantes de sua experiência, alunos de uma escola secundária inglesa, eram colocados numa situação, na qual ape- nas um esforço visando diferenciar positivamente seu grupo em relação a um outro lhes permitiria o acesso a uma identidade positiva. De fato, nessa situação era-lhes impossível tentar outra forma de melhorar sua sorte individual, portanto, de recorrer a qualquer tipo de estratégia de mobilidade individual, o que os levava à utilização de estratégias mais coletivas.

Um estudo sistemático impõe-se sobre o futuro destas considerações societais entre os numerosos autores que se dizem adeptos da teoria da identidade social. De acordo com as evidências, apenas uma minoria dentre eles se refere a uma abordagem societal, como é o caso no Quebec, em um livro de Taylor e Maghaddam (1987) e em um capítulo de Guimond e Tougas, (1994). Sem dúvida, não é por acaso que essas considerações societais sejam levadas a sério em um país onde povos nativos (Americanos autóctones), povos fundadores (anglo e francofônicos) e novas populações de imigrantes tentam agora redefinir as regras da vida em comum.

O paradigma de Tajfel, no momento atual, é freqüentemente assimilado a uma teoria de auto-categorização que não necessariamente evoca hipóteses de ordem societal. É o caso, por exemplo, quando esta teoria é utilizada por Turner (1987) para dar conta das dinâmicas de articulação das identificações regionais, nacionais e européias. Recentemente argumentamos que uma tal concepção da teoria da identidade social é insuficiente para dar conta das relações entre essas dinâmicas identitárias. É preciso, necessariamente, nela introduzir análises sobre as concepções societais dos respondentes (Doise \& Devos, 1999), sobre suas ideologias e projetos políticos que eles desenvolvem em relação a uma unificação européia.

\section{Psicologia societal e representações sociais}

Retornemos agora ao meu terceiro mestre, aquele com o qual comecei a trabalhar há quase 40 anos. Refiro-me a Moscovici, com o qual mantenho ainda contatos regulares. Resumo aqui seu ponto de vista sobre a psicologia social recorrendo a um artigo que ele publicou há uns 10 anos.

Nesse artigo, ele admite que é tão difícil teorizar sobre sua própria prática quanto "se observar passear pela rua através da janela de sua própria casa". Ainda, ele se declara também consciente do fato que "uma boa concepção da ciência não leva necessariamente a praticar uma boa ciência".

Retenho aqui, sobretudo, sua definição de objeto de estudo da psicologia social. De fato, este objeto seria, em parte, já tratado pela psicologia política ou econômica, pelo interacionismo simbólico, pela ethnometodologia, pela psicologia do desenvolvimento e da linguagem. Por causa de uma relação privilegiada da psicologia social com a psicologia, os outros laços não são nem explicitados, nem assumidos. Entretanto, a origem da psicologia social deve ser buscada, preferencialmente, na sociologia, em Durkheim, Simmel ou Toennies, e na antropologia e não apenas na psicologia. Psicólogos como Wundt, Tarde, Freud, McDougall, Baldwin, Mead ou Lewin, pais fundadores da psicologia 
social, demandam por uma continuidade em relação as outras ciências sociais, sobretudo, a antropologia. Ao invés de considerar a psicologia social como um apêndice da psicologia, é preciso, antes de tudo, considerá-la como uma ponte para outros ramos do saber, sobretudo atualmente, quando a psicologia tem se desinteressado dos fatos sociais, focalizando os fenômenos biológicos.

Para Moscovici, em realidade é na vida com os outros que pensamento, sentimento e motivação humanos se desenvolvem. Nesse sentido, a psicologia social, utilizando-se de seus próprios métodos, particularmente os experimentais, deve tornar-se um tipo de antropologia da cultura moderna. Seus próprios métodos só deveriam ser utilizados quando há a possibilidade de extrapolarem para outras disciplinas "que se ocupam das mesmas questões, fornecendo-nos bases de dados e orientações teóricas".

Uma tal definição de objeto necessita superar a clivagem tradicional entre, de um lado, análises oriundas da psicologia e centradas no indivíduo e, de outro, análises econômicas e sociológicas que abordam a sociedade. Esses dois tipos de análises, apesar das tensões existentes entre elas, devem manter-se ligadas uma a outra. A realidade das relações entre o individual e o social necessita de modelos ternários, fazendo intervir o outro na construção desta realidade.

Em nossas negociações com o outro, com outros indivíduos e grupos, temos consciência que os processos se desenvolvem ao mesmo tempo dos dois lados. Daí a importância das representações sociais, constituindo uma parte importante da realidade social e a modulando. Eis aqui um objeto de estudo encontrado pela psicologia social do devir.

São, portanto, os estudos sobre as representações sociais, iniciados por Serge Moscovici (1961), que me parecem atualmente fornecer o quadro mais estimulante para construir uma psicologia societal imbricando o estudo dos sistemas cognitivos no nível do indivíduo no estudo dos sistemas relacionais e societais. $\mathrm{O}$ estudo das representações sociais preconizado por Moscovici necessita que se coloque em relação os sistemas cognitivos complexos do indivíduo com os metasistemas de relações simbólicas que caracterizam uma sociedade:

... vemos funcionar dois sistemas cognitivos, um que processa associações, inclusões, discriminações, deduções, quer dizer, o sistema operatório, e outro que controla, verifica, seleciona, com a ajuda de regras, lógicas ou não; trata-se de um tipo de metasistema que retrabalha a matéria produzida pelo primeiro (Moscovici, 1976, 254).

Ele incumbe precisamente os psicólogos sociais de estudar as relações entre essas regulações societais e funcionamentos cognitivos, para responder à questão: quais sistemas de comunicação característicos de uma sociedade atualizam ou favorecem quais funcionamentos cognitivos, em quais contextos específicos? Um vasto programa!

Tive a oportunidade, com Alain Clémence e Fabio LorenziCioldi, de propor um quadro teórico e metodológico para o estudo quantitativo das representações sociais. De uma maneira geral, definimos as representações sociais como prin- cípios organizadores das relações simbólicas entre indivíduos e grupos. Seu estudo remete a três hipóteses importantes.

Uma primeira hipótese é que os diferentes membros de uma população estudada partilham efetivamente certas crenças comuns concernentes a uma dada relação social. As representações sociais (RS) se constróem nas relações de comunicação que supõem referentes ou pontos de referência comuns aos indivíduos ou grupos implicados nessas trocas simbólicas.

Uma segundo hipótese refere-se à natureza das tomadas de posições individuais em relação a um campo de (RS). A teoria das representações sociais deve explicar como e porquê os indivíduos diferenciam entre si nas relações que eles mantêm com essas representações. Isto implica que essas variações nas tomadas de posição individuais são organizadas de uma maneira sistemática.

Uma terceira hipótese considera a ancoragem das tomadas de posição em outras realidades simbólicas coletivas, como as hierarquias de valores, as percepções que os indivíduos constróem das relações entre grupos e categorias e as experiências sociais que eles partilham com o outro.

O projeto da psicologia societal não implica apenas em um conhecimento dos problemas pertinentes elaborados pelas outras disciplinas, como a sociologia ou a antropologia, mas também em uma articulação de nossas análises com aquelas mais societais.

No âmbito das equipes que realizaram projetos já concluídos no quadro desse modelo de três fases, freqüentemente incluíam-se sociólogos ou psicólogos sociais de formação sociológica (cf. Clémence, 1994, Clémence, Doise et Lorenzi-Cioldi, 1994, Roux, Gobet, Clémence, Deschamps \& Doise, 1994). No âmbito teórico, a definição de representações sociais que proponho visa articular a teoria de Serge Moscovici com aquela de Pierre Bourdieu (Doise, 1985).

\section{Aportes da empiria nas pesquisas sobre os Direitos Humanos}

Nas páginas que se seguem, retomaremos, antes de tudo, as principais conclusões de nossas próprias pesquisas sobre as representações sociais dos Direitos Humanos (DH), completando-as com aquelas relatadas por outros colegas. Para a organização dessa apresentação, poderíamos escolher entre duas possibilidades: seja ordená-la em função das grandes questões levantadas na primeira sessão dessa contribuição; seja em função das três hipóteses teóricas sobre as RS que acabamos de evocar.

Finalmente, escolhemos uma apresentação que se mantém mais próxima de nossas pesquisas, abordando sucessivamente as três fases dos estudos sobre as representações sociais. Mas, à guisa de conclusão, para cada fase desenvolveremos algumas implicações dos dados que aqui são apresentados para uma problemática mais geral dos direitos humanos.

\section{O campo comum dos direitos humanos.}

Duas pesquisas, em particular, informam-nos, de forma mais explícita, acerca deste campo tal como ele é construído 
por extratos de diferentes países. Na primeira (cf. Clémence, Doise \& Lorenzi-Cioldi, 1994; Clémence, Doise, De Rosa \& Gonzalez, 1995), solicitamos a estudantes com idades entre 13 e 20 anos, habitando 4 diferentes países (Costa Rica, França, Itália e Suíça), que se pronunciassem sobre 21 situações de restrição de certos direitos em termos do esperado em $\mathrm{DH}$, sobre uma escala de 4 pontos (sim, certamente; sim, talvez; não exatamente; certamente não). Os resultados são bastantes convergentes, não há dúvida que nos 4 países, os estudantes estruturam suas respostas de uma forma semelhante, em torno de um conjunto de elementos que se encontram mais ou menos explicitados em textos oficiais como a Declaração Universal dos Direitos Humanos (DUDH). Na segunda pesquisa (Doise, Spini \& Clémence, 2000), reproduzimos para estudantes universitários de aproximadamente 30 países, dos 5 continentes, o texto da DUDH. Para cada artigo da Declaração solicitamos que respondessem às escalas concernentes à importância atribuída ao artigo, sua implicação pessoal quanto ao respeito desse artigo e a eficácia atribuída ao governo e aos partidos políticos para fazer com que ele fosse respeitado. Os resultados para aproximadamente 20 países já foram analisados e podemos concluir que as respostas se organizam de maneira muito semelhante nos diferentes países, diferenciando os direitos segundo categorias utilizadas pelos redatores da DUDH (direitos individuais, direitos sociais, direitos sócio-econômicos, direitos a uma ordem societal).

Aos resultados desses dois estudos é preciso adicionar os resultados referentes a uma população mais restrita, os habitantes de Genebra (Doise \& Herrera, 1994). Contrariamente às pesquisas precedentes, esta pesquisa começava com questões abertas, convidando os participantes a enumerar e a descrever os Direitos Humanos (DH). Praticamente, todos os direitos enumerados poderiam ser colocados em relação com aqueles proclamados na DUDH.

A referência comum às definições oficiais dos DH parece, portanto, uma realidade bastante disseminada. Isto não significa, necessariamente, que todos os respondentes aderem sem reservas a um conjunto de direitos contidos na DUDH. Retomaremos mais adiante este problema, quando estudarmos as variações nas tomadas de posição individuais. Mas, assinalemos aqui que os textos oficiais limitam, de uma maneira importante, o leque dos DH, como é o caso particular da Convenção Européia. Ela anuncia, principalmente, os direitos individuais e prevê também a suspensão, pelo menos provisória, da maior parte dentre eles em certas situações excepcionais. Um estudo com entrevistas, realizado em Paris e na Suíça (Bechlivanou, Delmas-Marty, Doise, Duchesne, Gonzalez \& Lenoir, 1990) mostra também que uma tal visão restritiva é facilmente partilhada pela população interrogada.

No que se refere à questão da universalidade dos DH, as pesquisas mencionadas não podem apresentar conclusões definitivas. As populações estudadas não são absolutamente representativas do conjunto da população humana. Trata-se no máximo de estudos exequíveis. Mas, como indicam as pesquisas sobre valores, relatadas por Inglehart (1995) e efetuadas sobre amostras mais representativas, em 43 países (compreendendo $70 \%$ da população mundial), é possível generalizar nossa abordagem. Uma primeira conclusão a tirar nos parece ser a seguinte: um dos procedimentos a seguir para arbitrar o debate da universalidade é também o de interrogar os membros de culturas diferentes, apresentandolhes versões adaptadas de documentos oficiais (dos quais representantes de seus governantes são signatários). Uma outra conclusão que tiramos destas pesquisas relaciona-se à possibilidade de limitação dos direitos previstos pela Convenção Européia. Apenas as proteções contra a tortura e a escravidão, a legalidade dos delitos e das penas e a não retroatividade da lei penal estão nela garantidas de uma maneira global, assim como a interdição de expulsões coletivas. Não seria necessário relembrá-los, em todas as discussões interculturais sobre a universalidade dos DH?

\section{A variação das tomadas de posição individuais}

Nesta sessão, reportamos-nos, principalmente, àquelas pesquisas sobre as variações de tomadas de posição e, por consequiência, nos será possível estudar, na sequiência deste texto, as ancoragens em outras realidade simbólicas sociais. Mencionemos, entretanto, o interessante estudo de Rogers e Kitzinger (1995) que extraem, através de um método apropriado (técnica Q-sort), uma dezena de estruturas representacionais em um material originário de várias fontes e apresentado a 57 adultos, igualmente, de origens muito diferentes. Doise e Herrera (1994) descrevem, também, 6 fatores obtidos em uma análise fatorial textual de respostas livres fornecidas pelos participantes da pesquisa de Genebra. Estes fatores dão conta de explicar as tomadas de posição individuais em diferentes embates tradicionais, tais como aqueles opondo bens materiais e espirituais, liberdade e restrições de origens sociais, liberdade e igualdade.

Diaz-Veizades, Widaman, Little e Gibbs (1994) utilizaram, igualmente, a DUDH como base de um questionário sobre os DH. Entretanto, eles efetuam um importante trabalho de adaptação deste texto. Inicialmente, eles reformulam os artigos em 116 itens para os quais os estudantes expressavam, um a um, seu grau de acordo sobre uma escala de 7 pontos. Em seguida, eles eliminam todos os itens que não obtiveram uma saturação de pelo menos $.30 \mathrm{em}$ um dos 4 fatores obtidos numa análise de componentes principais, de forma tal que acabaram retendo apenas 38 itens para o estudo definitivo com 212 estudantes universitários e 42 adultos. Trata-se, portanto, claramente de uma pesquisa que privilegia o estudo da organização das variações inter-individuais, cuja lógica se manifesta nos 4 fatores. Estes fatores são descritos da seguinte maneira:

Fator 1: Todos os itens (...) referem-se ao acesso ou direito a um padrão de vida adequado (por exemplo: comida, habitação, cuidados médico). Este fator é chamado de Segurança Social.

Fator 2: (...) itens concernentes à aceitação limitada dos direitos individuais civil e político; uma outra forma de descrever o 
segundo fator seria dizer que ele refletiria uma orientação contra os direitos humanos. Este fator foi chamado de Restrição Civil.

Fator 3: O tema engloba (...) itens que juntos referem-se à igualdade, evidenciado mais claramente pelos itens concernentes à igualdade de acesso aos direitos básicos por todos os individuos, independentemente da raça, gênero ou crenças.

Fator 4: Dentre seis itens, quatro envolveram direitos de privacidade individual (...). Um item referia-se à educação (...) $e$ um outro referia-se à linguagem (...). Como a maioria dos itens, e aqueles com alta saturação, envolviam direitos à privacidade, denominados este fator de Privacidade (Diaz-Veizades, Widaman, Little \& Gibbs, 1994, pp. 317-321).

Em várias de nossas próprias pesquisas identificamos, igualmente, tais princípios organizadores de diferentes posições individuais, particularmente, na pesquisa já mencionada sobre as violações efetuada em quatro países. Os dois primeiros fatores são organizados pelos julgamentos sobre as violações que estão mais diretamente inscritas no campo oficial dos DH. As expectativas que mais contribuem com o primeiro fator referem-se à violação das liberdades das pessoas e da igualdade de direitos em matéria de estabelecimento, de expressão política, de informação e de religião. É interessante revelar que um item (obrigação de culto ou da missa para as crianças), cujo julgamento médio de expectativa foi fraco, inclui-se neste fator. $\mathrm{O}$ fator 2 refere-se à violação dos direitos das pessoas (direito à subsistência, à defesa jurídica, à assistência) e à proteção das crianças; estas violações se opõem à proibição de fumar que não está incluída nos registros dos DH. Os fatores de 3 a 5 referem-se, mais especificamente, às relações entre as pessoas. $\mathrm{O}$ fator 3 é orientado principalmente pela violação da igualdade entre o casal e, de forma mais marginal, pela violação dos direitos das crianças pelos pais. As saturações mais fortes no quarto fator são aquelas dos itens que evocam relações de poder, implicando em sanções aos desviantes, ou às minorias (ciganos, ladrões, estrangeiro com suspeita de homicídio e, de forma mais fraca, pessoas tendo baixos salários, prisioneiros que se agridem e ...os fumantes). Enfim, o último fator refere-se às relações sócio-econômicas (hospitalização forçada e desigualdade salarial), julgadas como estranhas ao campo dos DH e que se opõem à violação reconhecida dos $\mathrm{DH}$, tais como a violência sobre as crianças ou o encarceramento de adversários políticos.

$\mathrm{O}$ fato de existir referências comuns em relação aos $\mathrm{DH}$, não implica, por consequiência, que os indivíduos, entre si, avaliem os diferentes direitos da mesma maneira. Entretanto, em nosso estudo com o texto da DUDH, pudemos constatar que as tomadas de posição dos indivíduos se diferenciam em apenas dos 30 artigos: aqueles que atribuem mais importância aos direitos individuais, por exemplo, geralmente também atribuem mais importância a outras famílias de direito; aqueles que se comprometem mais com certos direitos, manifestam, também, um maior comprometimento com outros, e da mesma forma para as crenças na eficácia do governo. De uma certa maneira, a propósito do conjunto dos direitos, suas crenças e comprometimentos estavam forte- mente ligados, aparecendo em bloco. Aparentemente, esta relação bastante forte entre atitudes concernentes aos diferentes grupos de direitos não se enquadra com a variedade de tomadas de posição que acabamos de ilustrar com a ajuda dos dados de várias pesquisas. Retomaremos este problema quando falarmos da ancoragem e da contextualização nas representações sociais dos direitos humanos.

Neste momento, insistimos sobre uma outra fonte de variação. Ela nos foi confirmada em um estudo com os 30 artigos da Declaração Universal. Uma análise tipológica nos permitiu distinguir 4 tipos de posições em relação aos direitos humanos.

Assinalamos que uma tal tipologia foi obtida tratando tanto as respostas de 6.791 estudantes de 38 grupos nacionais, sem levar em conta o país de origem (análise pancultural) como controlando eventuais efeitos de suas origens, obtendo-se, para cada resposta, a média nacional (análise individual). Duas análises hierárquicas foram, então, efetuadas.

As duas análises mostraram um grupo de sujeitos (respectivamente $28 \%$ e $29 \%$ do conjunto) que obtiveram escores médios elevados em todas os itens: trata-se de simpatizantes da idéia de direitos humanos.

Um outro grupo de respondentes pode ser considerado como composto de céticos (respectivamente $21 \%$ e $18 \%$ do conjunto). Suas respostas são menos favoráveis em todos os itens.

Um outro grupo não comprometido (respectivamente $28 \%$ et $28 \%$ do conjunto) deu respostas bastantes baixas em diferentes itens de implicação pessoal, mas ligeiramente mais elevado nos itens concernentes à implicação do governo.

Enfim, os sujeitos do último grupo (respectivamente 23\% e $25 \%$ do conjunto) consideram, ao mesmo tempo, que os direitos humanos lhes concernem mais diretamente no nível pessoal e, ao mesmo tempo, que não é fácil para o governo fazer qualquer coisa. Esta estrutura de resposta seria típica dos personalistas.

\section{Ancoragem e contextualização das representações sociais dos direitos humanos}

Em nossa apresentação da teoria das representações sociais distinguimos três tipos de ancoragens (Doise, 1992). A primeira foi praticada tanto por Diaz-Veizades e seus colegas (1994), como por nós mesmos. Diaz-Veizades mostra, por exemplo, que os indivíduos que privilegiam uma concepção dos direitos humanos limitada por restrições externas obtêm também escores elevados nos itens nacionalistas e escores baixos nos itens internacionalistas e de liberdades civis. Eles têm, também, simpatias políticas mais republicanas do que democratas. Por outro lado, aqueles que aderem a uma concepção dos direitos humanos favorável à segurança social são, também, mais internacionalistas nos Estados Unidos e suas simpatias se dirigem para os democratas.

Nas análises dos resultados do estudo com os 30 artigos efetivamos, sobretudo, uma análise da ancoragem, combinando a ancoragem nos valores e nas percepções do meio social e, particularmente, nos conflitos que os perpassam e 
que podem envolver diretamente os respondentes. Constatamos que a adesão prioritária a valores universais e de harmonia social está sistematicamente em relação com uma representação mais favorável e com um comprometimento mais pessoal em relação aos direitos humanos, enquanto que um posicionamento oposto é acompanhado de ceticismo. Ainda, uma consciência e uma experiência mais aguda de conflitos e de injustiça conduziriam a um comprometimento mais pessoal, oposto a uma atitude governamentalista.

No estudo sobre as expectativas em relação aos direitos humanos, com amostras de jovens de 4 países, dois itens se mostraram particularmente importantes para dar conta da maneira pela qual os sujeitos traçam uma fronteira entre o que era esperado e não esperado em relação aos direitos humanos. Esses itens se referiam aos direitos das pessoas frente ao poder político e econômico. Por exemplo, os alunos que tinham uma visão restrita das expectativas em relação aos direitos humanos eram também aqueles que achavam normal que uma empresa, antes de contratar um empregado, investigasse sua religião, sua maneira de viver, seu possível engajamento sindical, sua ficha judicial, sua saúde e que atribuíam, também ao governo, tais poderes de investigação.

No que diz respeito à ancoragem nas experiências sociais, é preciso, evidentemente, assinalar os efeitos da nacionalidade, bastante evidentes no estudo com os 38 grupos nacionais. Se a pertença ao grupo japonês ou indiano parece levar a uma atitude de ceticismo, uma concepção mais personalista estaria ligada à pertença a certos grupos nacionais caracterizados por um fraco índice de desenvolvimento econômico e por uma abundância de violações dos direitos humanos.

\section{Outras convergências em direção a uma psicologia societal}

Os múltiplos contatos estabelecidos ao longo de mais de 30 anos me encorajaram, constantemente, a trabalhar com uma psicologia societal. Não posso citar todos, mas o fato de que colegas como Glynis Breakwell e Colin Rowett (1982) tenham chegado a uma distinção em quatro níveis, em suas análise do trabalho social, confortou-me na minha intenção. Mais tarde, um mesmo reforço me foi dado por Miles Hewstone (1989), que adaptou os quatro níveis de análise para sistematizar as pesquisas no âmbito da atribuição causal.

Outros colegas abriram-me perspectivas que levavam também a uma articulação de análises psicológicas e análises societais. Assim, Augusto Palmonari associou-me a suas pesquisas sobre a profissionalização dos psicólogos e convenceu-me, através de seus trabalhos, que é possível analisar problemas societais recorrendo aos instrumentos teóricos e metodológicos elaborados na psicologia social. Procedimento análogo é também praticado há bastante tempo por Jean-Pierre Deconchy $(1971,1989)$ estudando, por exemplo, a ortodoxia religiosa ou a ideologia.

Os próprios títulos dos livros de Jean-Léon Beauvois (1994), Tratado da servidão liberal ou de Nicole Dubois (1994) A norma da internalidade e o liberalismo evocam uma problemática societal, para não dizer política. Para caracterizar essas duas obras, permito-me emprestar uma citação de Jacques-Philippe Leyens no prefácio do livro de Nicole Dubois: "O livro de Nicole Dubois nos revela /.../ que um valor como a internalidade depende muito menos das capacidades cognitivas dos indivíduos do que do funcionamento da sociedade" (Leyens, 1994, p. 8). Efetivamente, nossas sociedades estão baseadas nas avaliações dos indivíduos em termos de autonomia e de responsabilidade. Os trabalhos recentes de Christian Staerklé (Staerklé, Clémence \& Doise, 1998) estendem os estudo dessa normatividade "democrática" ao campo dos julgamentos sobre os governantes e populações em um contexto internacional, opondo, sobretudo, os países democráticos ao resto do mundo.

Uma preocupação societal está presente também nas pesquisas de Fabio Lorenzi-Cioldi (1988, 1994), sobre os grupos 'coleção' e 'agregados'. Suas pesquisas realizadas nesse âmbito constituem-se em protótipos de uma psicologia societal: o processo psicológico de categorização atualizase diferentemente em função da evocação de grupos a um status sociológico diferente, dominantes ou dominados, masculinos ou femininos. Assim, efeitos não previstos pelo processo de categorização se produziriam quando da evocação da pertença a um grupo 'coleção', o qual faria co-variar diferenciações intra e inter-grupos; enquanto que a evocação da pertença a um grupo 'agregado' teria efeitos de acordo com uma definição mais corrente do processo de categorização, porque a acentuação das diferenças entre grupos caminharia junto com uma acentuação das semelhanças intra-grupos.

Patricia Roux (1999) promove, atualmente, uma evolução da questão das relações de gênero, propondo o conceito de ambigüidade normativa, para dar conta da condição de muitas mulheres em nossa sociedade que são levadas a demandar normas igualitárias e a reivindicar também uma nãodiscriminação, ao mesmo tempo em que assumem também a tarefa cotidiana de proteger as "boas relações" conjugais, relações que são freqüentemente desiguais e assimétricas, sobretudo, no que concerne o trabalho doméstico.

Se para indicar as convergências, eu citei, sobretudo, pesquisas realizadas na França ou na Suíça é pela simples razão que elas me são mais familiares e que elas foram também mais importantes para me encorajar a perseverar em uma psicologia societal. Isso não indica, entretanto, que meus contatos em psicologia societal não se estendam para além da francofonia. Eles se estendem até mesmo ao Brasil, desde que tomei conhecimento dos trabalhos de Angela Almeida (1999), sobre o fracasso escolar e de Leôncio Camino (1995), sobre as crenças em um mundo justo como fator oposto à militância política.

Essa enumeração de contatos está longe de ser exaustiva. Mas, acredito que todos os trabalhos citados têm em comum o fato de integrar em suas explicações hipóteses sobre os modos de funcionamento da sociedade e dos modos de funcionamento individuais. A meu ver, é exatamente isso que caracteriza uma visão societal da psicologia. 


\section{Conclusão}

Este cuidado em integrar, em uma mesma análise, os modos de funcionamento da sociedade e dos indivíduos é também o que diferencia a psicologia societal de muitas pesquisas realizadas no âmbito da psicologia política. As pesquisas em psicologia política podem, evidentemente, ser pesquisas em psicologia societal, mas não necessariamente o são. Elas podem muito bem aplicar modelos correntes na psicologia social ao estudo da escolha política, sem, entretanto, recorrer a qualquer análise do tipo societal (cf. o livro coletivo editado por Iyengar \& McGuire, 1993). Inversamente, o exemplo dos estudos sobre a identidade européia, abordado brevemente aqui, mostra que uma perspectiva societal pode incitar uma abordagem psicossocial tornar-se mais exaustiva em suas próprias explicações, completando, por exemplo, a teoria da identidade social por aquela de Sherif (1966), sobre os objetivos supra-ordenados ou aquela de Rabbie e Horwitz (1969), sobre o destino partilhado.

Piaget (1932, p. 279) foi, sem dúvida, um precursor, quando declarava, a propósito de sua análise da mentalidade primitiva, que não havia como retornar a uma "fase pré-sociológica da psicologia", mas que ele gostaria de "assinalar que nos quadros traçados pela sociologia há todo um interesse de restabelecer a análise psicológica: há atualmente muito mais paralelismo do que antagonismo entre os estudos sociológicos e as pesquisas psicológicas”. Isto foi escrito em 1932.

\section{Referências}

Almeida. A.M.O. (1999). Desenvolvendo competências em universos múltiplos. In M.G.T. Paz \& A. Tamayo. Escola, saúde e trabalho: estudos psicológicos. Brasília: EDUnB, 101-118.

Beauvois, J.-L. (1994). Traité de la servitude libérale. Paris: Dunod. Bechlivanou, G., Delmas-Marty, M., Doise, W., Duchesne S., Gonzalez, L. \& Lenoir, R. (1990). Discours juridique et discours ordinaire. La perception des droits de l'homme dans la société contemporaine. Archives de politique criminelle, 12, 145-166.

Breakwell, G.M. \& Rowett, C. (1982). Social work: the social psychological approach. Wokingham: Van Nostrand Reinhold.

Camino, L. (1995). Da agressão individual às ações coletivas e políticas: Reflexões sobre a construção do Núcleo de Estudos em Comportamento Político. Textos do Mestrado em Psicologia Social. João Pessoa: Universidade Federal da Paraíba.

Clémence, A. (1994). Solidarités sociales en Suisse. Lausanne: Réalités Sociales.

Clémence, A., Doise, W. \& Lorenzi-Cioldi, F. (1994). Prises de position et principes organisateurs des représentations sociales. In: C. Guimelli (Org.), Structures et transformations des représentations sociales. Paris: Delachaux et Niestlé.

Clémence. A., Doise, W. de Rosa, A.S. \& Gonzalez, L. (1995). La représentation sociale des droits de l'homme: une recherche internationale sur l'étendue et les limites de l'universalité. Journal International de Psychologie, 30, 181-212.

Deconchy, J.P. (1971). L'orthodoxie religieuse. Essai de logique psycho-sociale. Paris: Mouton.
Deconchy, J.P. (1989). Psychologie sociale, croyances et idéologies. Paris: Méridiens Klincksieck.

Diaz-Veizades, J., Widaman, K.F., Little, T.D., Gibbs, K.W. (1994). The measurement and structure of human rights attitudes. Journal of Social Psychology, 135, 313-328.

Doise W., (1980), Levels of explanation in the European Journal of Social Psychology, European Journal of Social Psychology, 10, 213-231.

Doise W., (1985), Les représentations sociales: définition d'un concept. Connexions, 45, 243-253.

Doise, W. \& Devos, T. (1999). Identité et interdépendance: Pour une psychologie sociale de l'Union Européenne. Psychologie et Société, 1, 11-23.

Doise, W. \& Herrera, M. (1994). Déclaration universielle et représentations sociales des droits de l'homme: une étude à Genève. Revue Internationale de Psychologie Sociale, 7, 87-107.

Doise, W. (1982). L'explication en psychologie sociale. Paris: PUF.

Doise, W. (1992). L'ancrage dans les études sur les représentations sociales. Bulletin de Psychologie, XLV, 405, 189-195.

Doise, W. (2000). Les droits de l'homme comme représentations sociales de contrats d'interdépendance. In C. Garnier \& M. L. Rouquette (Orgs.), Représentations sociales et Éducation, Montréal: Éditions Nouvelles.

Doise, W., Spini, D. \& Clémence, A. (2000). Human rights studied as social representation in a cross-national context. European Journal of Social Psychology, 29, 1-29

Doise, W.; Lorenzi-Cioldi, F. (1989), Sociologues et psychologie sociale, Revue Européenne des Sciences Sociales, 27, 147-196.

Dubois, N. (1994). La norme d'internalité et le libéralisme. Grenoble: PUG.

Garnier, C. \& Rouquette, M-J. (2000). Représentations sociales et éducation. Montréal: Éditions Nouvelles.

Guimond, S. \& Tougas, F. (1994). Sentiments d'injustice et actions collectives: la privation relative. In: R.Y. Bourhis \& J.P. Leyens, Stéréotypes, discrimination et relations intergroupes. Liège: Mardaga.

Hewstone, M. (1989). Causal attribution. Oxford: Blackwell.

Higgins, E.T. \& Kruglanski, A.W. (1996). Social Psychology. Handbook of Basic Principles. NY: Guilford.

Iyengar, S. \& McGuire, W.J. (1993). Explorarions in Political Psychology. London: Duke.

Leyens, J.-P. (1994). Préface. In N. Dubois, La norme d'internalité et le libéralisme. Grenoble: PUG.

Lorenzi-Cioldi, F. (1988). Individus dominants et groupes dominés. Images masculines et féminines. Grenoble: PUG.

Lorenzi-Cioldi, F. (1994). Les androgynes. Paris: PUF.

Moscovici, S. (1961/1976). La psychanalyse. Son image et son public. Paris: PUF.

Moscovici, S. (1988). La Machine à Faire des Dieux. Paris: Fayard.

Mugny, G. \& Doise, W., (1979), Niveaux d'analyse dans l'étude expérimentale des processus d'influence sociale, Social Science Information, 18, 819-876.

Piaget, J. \& Weil, A.M. (1951). Le développement chez l'enfant, de l'idée de patrie et des relations avec l'étranger. Bulletin Intenational des Sciences Sociales, 3, 605-621.

Piaget, J. (1932). Le jugement moral chez l'enfant. Neuchâtel: Delachaux et Niestlé. 
Piaget, J. (1965). Etudes sociologiques. Genève: Droz.

Piaget, J. (1997). L'éducation morale à l'école. De l'éducation du citoyen à l'éducation internationale. Paris: Anthropos.

Rabbie, J.M.; Horwitz, M. (1969). The arousal of ingroup-outgroup bias by a chance win or loss. Journal of Personality and Social Psychology, 13, 269-277.

Rateau, P. \& Rouquette, M.L. (1998). Compte rendu du XXVIè congrès interaméricain de psychologie. Revue Internationale de Psychologie Sociale, 11, 173-176.

Rogers, R.S. \& Kkitzinger, C. (1995). ). A decalogue of human rights: what happens when you let the people speak. Social Science Information, 34, 87-106.

Roux, P., Gobet, P., Clémence, A., Deschamps, J.C. \& Doise, W. (1994). Stéréotypes et relations entre générations. Lausanne: Institut des Sciences Sociales et Pédagogiques.

Sherif, M. (1966). In Common Predicament. Boston: Houghton Mill.

Staerklé, C., Clémence, A. \& Doise, W. (1998). Representation of human rights across different national contexts: The role of democratic and non-democratic populations and governments. European Journal of Social Psychology, 28, 207-226.
Tajfel, H. \& Wilwes, A.L. (1963).Classification and quantitative judgment. British Journal of Psychology, 54, 101-114.

Tajfel, H. (1959). Quantitative judgement in social perception. British Journal of Psychology, 50, 16-29.

Tajfel, H. (1972). La catégorisation sociale. In S. Moscovici (Org.) Introduction à la psychologie sociale. Paris: Larousse.

Tajfel, H. (1974). Social identity and intergroup behaviour. Social Science Information, 13, 65-93.

Tajfel, H. (1975). The exit of social mobility and the voice of social change. Social Science Information, 14, 101-118.

Tajfel, H., Billig, M., Bundy, R.P. \& Flament, C. (1971). Social categorisation and intergroup behaviour. European Journal of Social Psychology, 1, 149-178.

Tajfel, H., Sheikh, A.A. \& Gardner, R.C. (1964). Content of stereotypes and the inference of similarity between members of stereotyped groups. Acta Psychologica, 22, 191-201.

Taylor, D.M. \& Moghaddam, F.M. (1987). Theories of intergroup relations: International social psychological perspectives. NY: Praeger.

Turner, J.C. (1987). Rediscovering the Social Group. A Self-Categorization Theory. Oxford: Blackwell.

Recebido em 23.10.2001

Primeira decisão editorial em 25.02.2002

Versão final em 14.05.2002

Aceito em 16.05.2002 